\title{
Clinical predictors of response to immunomodulators for multiple sclerosis
}

\author{
Preditores clínicos de resposta aos imunomoduladores em esclerose múltipla \\ Guilherme Sciascia do Olival', Leonardo Ciciarelli Pereira Lima², Gabriel Paiva Silva Lima ${ }^{1}$,Charles Peter Tilbery ${ }^{3}$
}

\begin{abstract}
Objectives: To determine, based on clinical criteria, the proportion of multiple sclerosis (MS) patients responsive to immunomodulators (RI) and nonresponsive to immunomodulators (NRI), and to ascertain whether clinical and epidemiological data differs between RI and NRI patient groups. Methods: Patients were assessed on rate of exarcerbations per year, for the period before and after commencement of treatment. The RI and NRI groups were compared for several clinical and epidemiological characteristics. Discussion and conclusion: A total of $31.4 \%$ of the patients were nonresponders to the immunomodulatory treatment. The main predictors of immunomodulatory response were early diagnostic and commencement of therapy and high rate of annual exacerbations prior to treatment. Given the arsenal of medication options available for MS management, screening potential candidates for different therapeutic approaches are critical to optimize evolution of patients with the disease.
\end{abstract}

Key words: multiple sclerosis, immunomodulators, predictors.

\section{RESUMO}

Objetivos: Avaliar por meio de critérios clínicos, a proporção de pacientes com esclerose múltipla (EM) responsivos aos imunomoduladores (RI) e não responsivos aos imunomoduladores (NRI) e avaliar se dados clínicos e epidemiológicos são distintos nesses dois grupos. Métodos: Os pacientes foram avaliados quanto à taxa de surtos por ano no período antes e após o início do tratamento. Diversas características clínicas e epidemiológicas foram comparadas entre os pacientes RI e NRI. Discussão e conclusão: Em nossa população, 31,4\% dos pacientes não responderam ao tratamento com os imunomoduladores. Os principais preditores de resposta aos imunomoduladores foram: diagnóstico e início precoce da terapia e elevada taxa de surtos anual antes do tratamento. Como existem várias opções medicamentosas disponíveis para o tratamento da EM, a identificação de candidatos potenciais para abordagens terapêuticas diferentes representa o ponto crucial para otimizar a evolução dos pacientes com essa doença.

Palavras-Chave: esclerose múltipla, imunomoduladores, preditores.

Multiple sclerosis (MS) is an autoimmune disease characterized by demyelinating inflammatory activity of the central nervous system. It is most prevalent in young adults between 20 and 40 years of age and constitutes a frequent cause of neurological dysfunction in this age group ${ }^{1}$.

Immunomodulatory therapy had been proven to be effective in modifying the natural course of the disease in patients with MS. Interferon beta (IFNb) and glatiramer acetate (GA) comprise the first line of therapy for MS and have seemed to reduce the rate of demyelination exacerbations compared to placebo in clinical trials ${ }^{2-5}$. However, not all patients are responsive to this treatment ${ }^{6}$.
The absence of biomarkers and the unpredictability of MS evolution leads to difficulty in distinguishing between response to therapy and disease activity ${ }^{7}$, requiring the use of clinical and imagiologic criteria to define the efficacy of therapies.

The presence of differences in clinical and epidemiological characteristics between responders (RI) and nonresponders (NRI) to immunomodulators has yet to be determined. The investigation of these clinical and epidemiologic characteristics is of primary importance, since the definition of clinical predictors of response to immunomodulators will allow the early identification of patients that should switch therapies.

\footnotetext{
${ }^{1}$ Neurologists of the Irmandade da Santa Casa de Misericórdia de São Paulo, São Paulo SP, Brazil;

${ }^{2}$ Graduate Student of the Santa Casa de São Paulo, Faculty of Medical Sciences, São Paulo SP, Brazil;

${ }^{3} \mathrm{MD}, \mathrm{PhD}$, Full Professor of the Santa Casa de São Paulo, Faculty of Medical Sciences, São Paulo SP, Brazil.

Correspondence: Guilherme Sciascia do Olival; Rua Piauí, 305 - Apto. 51;01241-001 São Paulo SP - Brasil; E-mail: guilhermesolival@gmail.com / guiolival@yahoo.com.br

Conflict of interest: There is no conflict of interest to declare.

Charles Peter Tilbery is member of Advisory Board of Biogen Idec and Merck Serono, participate in clinical trials for Bayer Schering, Merck Serono and Genzyme and has received honoraria for speaking at symposia from Bayer Schering, Merck Serono, Biogen Idec and Teva Neuroscience.

Received 10 May 2011; Received in final form 17 August 2011; Accepted 24 August 2011
} 
The aims of this study were:

- to determine, based on clinical criteria, the proportion of RI and NRI patients with MS seen at the Care Center for Multiple Sclerosis Treatment (CATEM) of the Neurology Discipline of the Department of Medical Sciences at Santa Casa de São Paulo Hospital;

- to ascertain whether clinical and epidemiological data, such as gender, age at MS onset, disease duration, and clinical evolution, differ between RI and NRI patient groups and identify which of them could be used as clinical predictors.

\section{METHODS}

The present study was previously approved by the Research Ethics Committee of Santa Casa de São Paulo Hospital.

\section{Inclusion criteria}

Patients diagnosed with relapsing-remitting MS between 1998 and 2008 were retrospectively selected for inclusion in the study, according to the following criteria: Poser's from 1998 to 20018; McDonald's from 2001 to 2005; and revised McDonald's criteria from 2005 to $2008^{10}$. During such period, those patients were treated at the CATEM of the Neurology Discipline of the Department of Medical Sciences of Santa Casa de São Paulo Hospital.

\section{Exclusion criteria}

All patients with irregular use of immunomodulators, treatment time of less than two years, poor anamnesis for the period prior to treatment, harboring the primary progressive form of MS, conversion to the secondary progressive form in less than two years, or use of medications other than IFNb or GA during the study period, were excluded from the study.

\section{Follow-up}

The decision to start treatment was made after the clinically defined diagnosis, meaning the second exacerbation. After commencement of treatment, patients were seen every three months and checked for the presence of symptoms and changes in the physical examination, consistent with exacerbation, and instructed to seek treatment at the service in the event of new symptoms. The expanded disability status scale (EDSS) was applied at each consultation. Patients were administered with the following immunomodulators: intramuscular IFNb $1 \mathrm{a}$ 30 mcg once per week ${ }^{11}$, subcutaneous IFNb 1 b 300 mcg on alternate days ${ }^{12}$, subcutaneous IFNb la 22 or 44 mcg three times per week ${ }^{13}$, and daily subcutaneous GA $20 \mathrm{mg}^{14}$. Medications were switched in the event of treatment failure or intolerable adverse reactions. The changes were made from IFNb lower dose to higher dose and, then, GA and vice versa.

\section{Criteria for clinical response to treatment}

Patients were assessed based on rate of relapses per year between disease onset and commencement of treatment, and rate of exacerbations after the beginning of treatment.

Patients were classified as RI if a $25 \%$ or greater reduction in exacerbation was evident after start of the treatment, given that this had been the response to placebo in the larger randomized trials ${ }^{2-5}$. Remaining patients were classified as NRI.

\section{Clinical parameters of response analyzed}

Patients were divided into RI and NRI groups and compared for the following clinical and epidemiological characteristics: age at disease onset; age at diagnostic and treatment commencement; time between disease onset and diagnostic/start of treatment; gender; interval between first and second relapses; relationship between rate of exacerbation per year in the period before and after treatment; and EDSS at the start and after two years of treatment.

\section{Statistical analysis}

Statistical analyses were performed using the SPSS $^{\circledR}$ Statistics software package, version 19.0.0 (SPSS, Chicago, USA), on an $\mathrm{IBM}^{\circledR}$ personal computer.

The association among categorical variables was assessed by the chi-square and Fisher tests. For continuous nonparametric and parametric variables, the Mann-Whitney and ANOVA tests were used, respectively, in comparisons between RI and NRI.

A 95\% confidence interval was used and a p-value $<0.05$ was considered statistically significant.

\section{RESULTS}

Of 430 patients registered between 1998 and 2008 at CATEM, 145 used immunomodulators for more than two years. Patients were excluded from this subgroup for the following reasons: four due to irregular immunomodulator use; ten with poor prior anamnesis data for a period prior to the study; two with primary progressive form of MS; and eight subjects that converted to the secondary progressive form. This gave a total study sample of 121 patients.

The distribution of immunomodulators in the initial course of treatment was: 22 patients in intramuscular IFNb 1a 30 mcg once per week; 38 in subcutaneous IFNb 1b 300 mcg on alternate days; 39 in subcutaneous IFNb la 22 or 44 mcg three times per week; and 22, subcutaneous GA $20 \mathrm{mg}$ daily. From among these patients, 51 switched treatment over to another immunomodulator during treatment, with 23 of these cases being due to adverse effects and 28 for clinically-defined treatment failure. The main collateral effects reported were influenza symptoms and skin reactions at injection sites. None of these patients received any other 
disease-modifying therapy, such as azathioprine, methotrexate, or natalizumab.

\section{Response to immunomodulators}

The proportion of RI was 83 patients $(68.6 \%)$ and the NRI was 38 (31.4\%), based on the clinical criteria of a $25 \%$ or greater reduction in exacerbation.

Table contains the clinical parameters of response to the immunomodulators evaluated.

\section{Clinical characteristics in relation to response to immunomodulators}

Comparing the RI and NRI patient groups, no difference for age at disease onset $(\mathrm{p}=0.54)$ or age at diagnostic and treatment onset $(p=0.96)$ was found. However, longer time between disease onset and diagnostic/therapy beginning commencement was found in the NRI Group (6.1 years, on average) compared to the RI Group (3.5 years, on average), with $\mathrm{p}<0.001$. No differences were found between men and women $(\mathrm{p}=0.89)$.

The interval between the first and second exacerbations was not associated with response to medications. The annual rate of relapses prior to treatment was 1.1 in $\mathrm{RI}$ greater than 0.5 in NRI, and the annual rate of exacerbations after treatment was 0.3 in RI lower than 0.9 in NRI $(p<0.001)$.

Both groups had the same rating on the EDSS at treatment commencement and showed increased ratings during the study period ( $\mathrm{p}=0.39$ ). The EDSS rating in the NRI Group rose from 1.6 to 3.1 after two years of treatment, whereas the RI Group rating increased from 1.4 to 1.7 over the same period.

\section{DISCUSSION}

In the present study, response to therapy was based on the clinical criteria of the rate of relapses per year before and after treatment. Patients exhibiting a $25 \%$ or greater reduction in exacerbations after therapy commencement were considered responsive to treatment, a figure based on the response to placebo described in previous trials ${ }^{2-5}$.

Functional assessment by the EDSS can be employed, but it has several limitations. First, the scale is nonlinear with a bimodal distribution. Second, the scale places greater emphasis on gait disabilities and is less sensitive for assessing other neurologic sequelae. Lastly, the scale tends to have a high inter-rater variability.

The neurological damage caused by MS is erratic and unpredictable, where in some cases minor lesions can lead to severe functional impairment, yet in other cases large lesions have minimal functional impact. Thus, rating response to therapy by quantifying dysfunction does not provide a realistic picture in that the aim of immunomodulators is not to cure, but to control the disease.

Based on this rationale, we proposed that response to immunomodulators be assessed by rate of relapses per year or by time interval between exacerbations in the same individual.

The aim of this study was not to compare efficacy of the medications, because head-to-head studies have previously confirmed, only the negligible difference among the drugs used $^{15-17}$.

In this study, $31.4 \%$ of the patients had an unsatisfactory reduction in annual rate of relapses, a finding comparable with rates reported in the literature ${ }^{6,18-20}$.

Waubant et al. ${ }^{18}$, in a study of similar design, comparing reduction in rate of exacerbations after immunomodulator therapy, found a proportion of $31 \%$ NRI.

Villoslada et al. ${ }^{19}$ conducted a study in Pamplona, Spain, and found that patients responsive to therapy were older and had longer intervals between disease onset and start of therapy, and they suggested that these data represent a patient group with a milder form of the disease from the outset.

Table. Clinical characteristics of multiple sclerosis patients in use of immunomodulators for at least two years.

\begin{tabular}{|c|c|c|c|c|}
\hline \multirow{2}{*}{ Characteristic } & All patients & Responsive & Nonresponsive & \multirow{2}{*}{$\mathrm{p}$-value } \\
\hline & $n=121$ & $n=83(31.4 \%)$ & $\mathrm{n}=38(68.6 \%)$ & \\
\hline Age at disease onset (years) & $28.0 \pm 8.7$ & $28.4 \pm 8.9$ & $27.8 \pm 8.3$ & 0.54 \\
\hline Age at diagnostic/treatment commencement (years) & $32.9 \pm 8.8$ & $32.6 \pm 8.1$ & $33.7 \pm 10.4$ & 0.96 \\
\hline $\begin{array}{l}\text { Time between disease onset and diagnostic/ } \\
\text { treatment (years) }\end{array}$ & $4.3 \pm 3.8$ & $3.5 \pm 3.4$ & $6.1 \pm 4.2$ & $<0.001$ \\
\hline Number of men (\%) & $23(19.0 \%)$ & $15(65.2 \%)$ & $8(34.8 \%)$ & 0.89 \\
\hline Number of women (\%) & $98(81.0 \%)$ & $68(69.4 \%)$ & $30(30.3 \%)$ & 0.89 \\
\hline Interval between $1^{\text {st }}$ and $2^{\text {nd }}$ exacerbation (years) & $2.4 \pm 2.5$ & $2.1 \pm 2.0$ & $3.5 \pm 3.5$ & 0.06 \\
\hline $\begin{array}{l}\text { Annual rate of exacerbations between disease onset } \\
\text { and treatment (exacerbations/year) }\end{array}$ & $0.9 \pm 0.6$ & $1.1 \pm 0.7$ & $0.5 \pm 0.3$ & $<0.001$ \\
\hline $\begin{array}{l}\text { Annual rate of exacerbation after treatment } \\
\text { commencement (exacerbations/year) }\end{array}$ & $0.2 \pm 0.2$ & $0.3 \pm 0.3$ & $0.9 \pm 0.5$ & $<0.001$ \\
\hline EDSS at treatment commencement & $1.5 \pm 1.2$ & $1.4 \pm 1.1$ & $1.7 \pm 1.5$ & 0.39 \\
\hline EDSS after two years of treatment & $2.1 \pm 1.7$ & $1.7 \pm 1.4$ & $3.1 \pm 2.2$ & 0.001 \\
\hline
\end{tabular}

Values expressed as mean \pm standard deviation unless specified otherwise.

MS: multiple sclerosis; EDSS: expanded disability status scale. 
In the present study, patient ages at disease onset and start of therapy were found not to differ between groups, although the assessment of delay to diagnostic and therapy onset reached statistical significance, with the NRI patients experiencing longer delays before diagnostic and start of the treatment.

This disparity with the literature may be explained by the difference in our study population and healthcare resources. Access to public health services in Brazil is limited. MS is less incident, and diagnosis can sometimes be delayed. Moreover, CATEM was the first MS center in the country and drew patients from regions throughout São Paulo state and even individuals from other states, who had harbored the disease for some time without treatment.

Therefore, we believe that in our milieu, patients with late diagnoses did not present milder forms of the disease, but delayed undergoing diagnosis due to difficulties in accessing reference centers in neurology.

EDSS studied in this casuistic revealed that RI and NRI started out with similar neurological compromise yet evolved differently.

The group of patients delaying diagnostic/treatment could represent individuals at a more treatment-resistant phase of MS, raising questions on the impact of long-term immunomodulatory therapy on the natural course of the disease. Studies assessing the impact of long-term immunomodulatory therapy use are lacking.

The rate of relapses also reached statistical difference, proving to be higher in RI patients prior to treatment. These data may reflect the fact that patients that benefit most from therapy are those with greater disease-related inflammatory activity. It is likely that the group of RI was differently than NRI since the beginning of the disease with a more inflammatory physiopathology and, therefore, more responsive to immunomodulatory treatment.

In MS patients that had two or more relapses prior to treatment, it is possible to calculate a rate of exacerbation per year, which is likely to be the natural history of disease. We propose that therapy can be considered effective or not based on this rate, instead of an absolute number of relapses.

However, we should note that while some patients have a milder form of the disease, groups with more aggressive forms must receive the earliest diagnosis and treatment possible and, in some cases, it may require a more potent therapy, since the response to the immunomodulators may not be sufficiently effective.

Likewise, increased attention is necessary to readily change therapy, if so required, in the group at higher risk for poor response to therapy, such as those whose diagnostic/ therapy commencement was delayed after the first exacerbation and with lower rate of annual exacerbations prior to treatment.
Some limitations apply to this study with reduced impact to the main findings. Potential bias in our data stem from the adoption of rate of exacerbation as a measure of response, given that the severity of exacerbations depends on the region with demyelination, while incomplete recovery after relapses could reflect the individual pathological pattern of the disease activity. Nevertheless, patients, who had converted to the secondary progressive form in less than two years, were excluded because their group had a low relapse rate per year and could be mistakenly regarded as RI. This strategy overestimated the proportion of RI up to $7 \%$. Other bias would be the different diagnosis criteria, which has changed during the assessed period. Also, these results are derived from a single center and there is no control group. Consequently, these results need to be reproduced in other cohorts.

In view of the erratic progression of MS and that the inflammatory phase can result in irreversible axonal loss, identification of patients who respond poorly to immunomodulators is pivotal in reconsidering other therapeutic approaches and consequent switches in first-line treatments or in indicating second-line therapies.

Although MS has long been suspected as constituting a primary autoimmune disease affecting the central nervous system (CNS), no single physiopathology has yet been established for the different mechanisms of damage. Differences in pathologies among patients suggest that clinically diagnosed MS may in fact comprise several different entities, all of which damage the CNS.

Thus, this raises the possibility that perhaps a substantial number of patients are not responsive to current therapy because their individual pathology is not responsive.

It can therefore be surmised that, at present, MS therapy is partially effective and has common inherent collateral effects, which limit its application. This situation is in part due to the absence of biomarkers of response to therapy. Biomarkers of response to therapy would allow the identification of the best RI, increasing the efficacy of drugs and preventing unnecessary treatment of NRI with these drugs, thereby reducing both costs and collateral effects. This scenario is set to become more complex with the emergence of novel drugs at phase 3 of clinical trials (e.g., laquinimod, rituximabe, daclizumabe) plus the development of combination therapy ${ }^{20,21}$.

In conclusion, in the population studied, $31.4 \%$ of the patients were NRI to the immunomodulatory treatment. The main predictors of immunomodulatory response were early diagnostic/commencement of therapy after the first exacerbation, and high rate of annual exacerbations prior to treatment.

Given the various medication options available for MS management, screening potential candidates for different therapeutic approaches are critical to optimize evolution of patients with the disease. 


\section{References}

1. Moreira M, Lana-Peixoto MA, Callegaro D, et al. Consenso expandido do BCTRIMS (Comitê Brasileiro de Tratamento e Pesquisa em Esclerose Múltipla) para o tratamento da esclerose múltipla: II. As evidências para o uso de glicocorticóides e imunomoduladores. Arq Neuropsiquiatr 2002;60:875-880.

2. Group TIbS. Interferon beta-1b is effective in relapsing-remitting multiple sclerosis. Neurology 1993;43:655-661.

3. Jacobs L, Cookfair D, Rudick R. Intramuscular interferon beta-1a for disease progression in relapsing multiple sclerosis. Ann Neurol 1996;39:285-294.

4. PRISMS PoRaDblb-aSiMS. Randomised doubled-blind placebocontrolled study of interferon beta-1a in relapsing/remitting multiple sclerosis. Lancet 1998;352:1498-1504.

5. Bornstein M, MillerA,SlagleS, etal.A pilottrial ofCOP 1 in exacerbatingremitting multiple sclerosis. N Engl J Med 1987;317:408-414.

6. Rio J, Nos C, Tintoré M, et al. Defining the response to interferon-b in relapsing-remitting multiple sclerosis patients. Ann Neurol 2006;59:344-352.

7. Martinez-Forero I, Pelaez A, Villoslada P. Pharmocogenomics of multiple sclerosis: in search for a personalized therapy. Expert Opin Pharmacother 2008;9:1-15.

8. Poser C, Paty D, Scheinberg L, et al. New diagnostic criteria for multiple sclerosis: guidelines for research protocols. Ann Neurol 1983;13: 227-231.

9. McDonald W, Compston A, Edan G, et al. Recommended diagnostic criteria for multiple sclerosis: guidelines from the International Panel on the diagnosis of multiple sclerosis. Ann Neurol 2001;50:121-127.

10. Polman C, Reingold S, Edan G, et al. Diagnostic criteria for multiple sclerosis: 2005 revisions to the "McDonald Criteria". Ann Neurol 2005;58:840-846.
11. Avonex (interferon beta-1a). Prescribing information. Cambridge, MA: Biogen Inc.; 1996.

12. Betaferon (interferon beta-1b). Prescribing information. Richmond, CA: Berlex Laboratories; 1993.

13. Rebif (interferon beta-1a). Prescribing information. Oakville. Ontario: Serono, Canada; 1998.

14. Copaxone (acetato de glatirâmer). Prescribing information PetahTikva, IS: Teva laboratories; 1990.

15. O'Connor P, Filippi M, Arnason B, et al. 250 microg or 500 microg interferon beta-1b versus $20 \mathrm{mg}$ glatiramer acetate in relapsingremitting multiple sclerosis: a prospective, randomised, multicentre study. Lancet Neurol 2009;8:889-897.

16. Mikol D, Barkhof F, Chang P, et al. Comparison of subcutaneous interferon beta-1a with glatiramer acetate in patients with relapsing multiple sclerosis (the REbif vs Glatiramer Acetate in Relapsing MS Disease [REGARD] study): a multicentre, randomised, parallel, openlabel trial. Lancet Neurol 2008;7:903-914.

17. Cadavid D, Wolansky L, Skurnick J, et al. Efficacy of treatment of MS with IFNbeta-1b or glatiramer acetate by monthly brain MRI in the BECOME study. Neurology 2009;72:1976-1983.

18. WaubantE,Vukusic S, GignouxL.Clinical characteristics of responders to interferon therapy for relapsing MS. Neurology 2003;61:184-189.

19. Villoslada P, Oksenberg IR, Rio J, Montalban X. Clinical characteristics of responders to interferon therapy for relapsing MS. Neurology 2004;62:1653.

20. Pozzilli C, Prosperini L. Clinical markers of therapeutic response to disease modifying drugs. Neurol Sci 2008;29(Suppl):S211-S213.

21. Graber JJ, McGraw CA, Kimbrough D, Dhib-Jalbut S. Overlapping and distinct mechanisms of action of multiple sclerosis therapies. Clin Neurol Neurosurg 2010;112:583-591. 